\title{
Cerebral dysautonomy as a clinical repercussion in children with traumatic brain injury
}

\author{
Jassiara Soares da Silva ${ }^{1}$, Carlos Umberto Pereira ${ }^{2}$, Nicollas Nunes Rabelo ${ }^{1}$
}

Received: 21 April 2020 / Published: 01 August 2020

\begin{abstract}
Introduction: Dysautonomia or Paroxysmal Sympathetic Hyperactivity (PSH) affects more than $50 \%$ of patients suffering from severe traumatic brain injury (TBI), which is a major cause of morbidity and mortality in children under 12 years. The goal is to demonstrate that PSH is established as a consequence in children with severe brain trauma.

Methodology: Forty articles were found in databases such as LILACS, Elsevier and Scielo that address the theme, excluding those that addressed the TBI in adults and including those that addressed the theme in the pediatric context and published about the $\mathrm{PSH}$, published until the year of 2019.

Results: Severe TBI is established as a common cause of hospitalization of children and $\mathrm{PSH}$ as a common consequence. Diagnosis and management of this complication require the help of tools such as "PSHAssessment Measure (PSH-AM)", which has criteria that facilitate the exclusion of other possible causes and guide the treatment. Non-pharmacological therapeutic measures include control of room temperature and low sensory and pharmacological stimuli to deal with symptoms, such as drugs such as opioids, gabaergic agonists, benzodiazepines and adrenergic antagonists.

Conclusion: Severe TBI, a common pediatric emergency, can be considered a predictor of PSH. Even though there is no consensus on the diagnosis, PSH-AM proves to be a reliable alternative to professionals dealing with conditions that may or may not correspond with post trauma dysautonomia. This
\end{abstract}

\footnotetext{
${ }^{1}$ Neurosurgery Department, UniAtenas University Center, Paracatu - MG, Brazil

${ }^{2}$ Department of Neurosurgery of FBHC and Neurosurgery Service, Aracaju, Sergipe, Brazil
}

To whom correspondence should be addressed: Nícollas Nunes Rabelo, MD [E-mail: nicollasrabelo@hotmail.com]

Journal homepage: www.sbnped.com.br makes it possible to determine not only the child's clinical condition but also the best therapy to apply.microbiology team. This situation reinforces the need for frequent update to the most recent literature available.

Key words: Autonomic Nervous System; Brain injuries; Child; Primary dysautonomias.

\section{Introduction}

Dysautonomia tends to affect $75 \%$ of patients who are victims of severe traumatic brain injury (1). This is also known as a state of Paroxysmal Sympathetic Hyperactivity (PSH), which according to Baguley is the set of signs and symptoms in patients after severe worrying brain injury, with a transient elevation of heart rate and respiratory, blood pressure, temperature sweating, and diaphoresis and muscle tone and adoption of an extensor posture (1-3). This disorder usually manifests prematurely, still under intensive care, and may persist after hospital discharge (1).

In this context, physical-brain trauma is an important cause of morbidity and mortality in children under 12 years old (4). In Brazil, it is no different, establishing itself as the leading cause of death in children over five years of age (4). TBI is a relevant etiology of head injury, with a significant number of hospitalizations in Intensive Care Units (ICU), with a considerable morbidity and mortality rate of children, with dysautonomy as a probable post-traumatic complication (4-7). The purpose of this review is to show that PSH tends to be a common complication after severe brain trauma, especially in children.

\section{Methods}

For this literature review, a literature search was carried out in national and international databases such as LILACS, Elsevier and Scielo to obtain 
scientific articles published until 2019, in order to map the largest number of publications relevant to the theme. The descriptors used were: "TBI in children", "Disautonomia" and "Paroxysmal sympathetic hyperactivity", with the crossing between both after an individualized search. To meet the proposed objectives, the articles that related to severe traumatic brain injury in the pediatric context and on PSH were established as inclusion criteria. This procedure was necessary because there are works that deal with TBI but in adulthood, not being the focus of the paper Therefore, 40 articles were selected by crossreference.

\section{Results}

\section{Disautonomy}

After any trauma there is a metabolic response, which culminates in hemodynamic changes in which there is tachycardia, hypertension and directing blood to noble organs such as the brain (8). Before the recovery of trauma, it is expected that there is a lowering of this response and consequently sympathetic activity, which when it does not occur may indicate the non-resolution of the initial trauma, which is common after a traumatic brain injury (8).

Paroxysmal sympathetic and muscular hyperactivity after TBI, first described in 1929 by Penfield, is called dysautonomia $(8,9)$. This culminates with increased heart rate and respiration, increased temperature and blood pressure, sweating and muscle modifications such as dystonia, stiffness, spasticity and posture such as flexion of the upper limbs and extension of the lower limbs (decortication) and extension of the upper and lower limbs (decerebration) (8-10).

PSH presents a three-step clinical course (8). At first, right after the trauma, one can hardly predict whether or not the patient will develop it; in the second, the first signs appear and when sweating disappears after more than 70 days of trauma. There is the third stage in which motor abnormalities may persist (8).

\section{Traumatic brain injury and its relationship with age groups}

In the United States, there are an estimated more than 500 thousand new cases of TBI annually, where about $10 \%$ of these die before receiving hospital care and around 20.000 die after being treated and $86 \%$ progress to neurological sequelae with varying degrees of severity, as dysautonomia (8). In severe TBI, in which critically ill patients are at high risk of bodily functional demotion and death, $\mathrm{PSH}$ is a complication (11-13). This is common in patients between 5 and 35 years old, and corresponds to almost $20 \%$ of deaths in this age group $(13,14)$. TBI, a common cause of emergency hospitalization of children, may have a focal lesion - characterized by: contusion, intracranial bleeding and rupture; or diffuse lesion in which there is a focal axonal involvement and volumetric increase of neural tissue $(4,14,15)$.

Severe diffuse axonal injury (DAl) as a
predisposing factor

Severe diffuse axonal injury (AID), common in TBI, is a predisposing factor to the development of $\mathrm{PSH}$, whose incidence exceeds $10 \%$ in childhood (14). In this pattern of manifestation, the central autonomic centers are injured causing the interruption of numerous tracts and, thus, the functional balance of the Autonomic Division of the Nervous System (ADNS) is compromised, resulting in a sympathetic hyperstimulation and, consequently, in the release of more catecholamines providing the dysautonomic state $(15,16)$.

Typical clinical manifestations detectable in children

Signs and symptoms resulting from systemic involvement of different organs, and hypertension, hyperhidrosis and involuntary repetitive movements of the torsion muscles were reported as the most frequent in the pediatric population $(15,17)$. Since these appear days after the injury and may persist for weeks if not properly applied or in comatose patients (18).

\section{Prognostic Aspect}

The dysautonomia, significantly impacts on the prognosis of the patient after brain trauma, due to numerous crises (15). The recovery process of children with central autonomic dysfunction depends on long hospitalizations, which does not exclude a possible worsening of cognitive-motor function $(16,17)$. Evolving symptoms may lead to or correlate with hyperthermia, weight loss, heterotrophic ossification, cardiac deterioration, and immune system deficiency (16).

\section{Detection mechanism}

Given the difficulty in concluding the diagnosis, given that clinical situations that generate paroxysmal sympathetic responses such as sepsis, pain and drug withdrawal may coexist, detection is by exclusion $(9,12)$. However, in order to facilitate the diagnostic process, a device called "PSH-Assessment Measure (PSH-AM)" was created, establishing criteria to facilitate and guide the management of patients who evolved to PSH. Even this one in its genesis assesses adults is proven adaptable to the pediatric context $(3,10,11,16)$. This tool has two daily assessment devices, the Clinical Characteristics Scale (CCS), which ranges from 0 to 3 points where the higher the final score of the variables, the more severe the 
Table 1 - Paroxysmal Sympathetic Hyperactivity Assessment Measurement

\begin{tabular}{|c|c|c|c|c|}
\hline Clinical Characteristics Scale (CCS) & 0 & 1 & 2 & 3 \\
\hline Heart rate (/ min) & $<100$ & $100-119$ & $120-139$ & $\geq 140$ \\
\hline Respiratory Rate (/ min) & $<18$ & $18-23$ & $24-29$ & $\geq 30$ \\
\hline Systolic blood pressure $(\mathrm{mmHg})$ & $<140$ & $140-159$ & $160-179$ & $\geq 180$ \\
\hline Temperature $\left({ }^{\circ} \mathrm{C}\right)$ & $<37$ & $37-37,9$ & $38-38,9$ & $\geq 39$ \\
\hline Sweating & Absent & Light & Moderate & Accented \\
\hline Posture during episodes & Absent & Light & Moderate & Accented \\
\hline \multicolumn{5}{|c|}{ Subtotal CCS } \\
\hline \multicolumn{5}{|c|}{ Diagnostic Probability Tool (DPT) - one point for each feature present } \\
\hline \multicolumn{5}{|l|}{ Simultaneously occurring clinical features } \\
\hline \multicolumn{5}{|l|}{ Episodes are paroxysmal in nature } \\
\hline \multicolumn{5}{|c|}{ Sympathetic hyperreactivity to normally non-painful stimuli } \\
\hline \multicolumn{5}{|c|}{ Persistent characteristics for 3 or more consecutive days } \\
\hline \multicolumn{5}{|c|}{ Persistent features for 2 or more weeks after brain injury } \\
\hline \multicolumn{5}{|c|}{ Persistent features despite treatment of alternative differential diagnoses } \\
\hline \multicolumn{5}{|c|}{ Medication given to reduce sympathetic features } \\
\hline \multicolumn{5}{|l|}{ Two or more daily episodes } \\
\hline \multicolumn{5}{|c|}{ Absence of parasympathetic features during episodes } \\
\hline \multicolumn{5}{|l|}{ No other presumed cause of appeal } \\
\hline \multicolumn{5}{|l|}{ Previously acquired brain injury } \\
\hline \multicolumn{5}{|c|}{ Subtotal DPT } \\
\hline \multicolumn{5}{|l|}{ Combined Total (CCS + DPT) } \\
\hline \multirow{3}{*}{ PSH diagnostic probability } & \multicolumn{2}{|c|}{ Unlikely } & $<8$ & \\
\hline & \multicolumn{2}{|c|}{ Possible } & \multicolumn{2}{|c|}{$8-16$} \\
\hline & \multicolumn{2}{|c|}{ Likely } & \multicolumn{2}{|l|}{$\geq 17$} \\
\hline
\end{tabular}

Source: adapted from Baguley et al. (2014)

dysautonomic involvement; and the Diagnostic Probability Tool (DPT) that allows the differential diagnosis to be performed, whose score can vary from 0 to 11 points, with one point for each positive item (Table 1) $(10,11)$.

There is still no consensus on these standards, but it is accepted by a significant portion of health professionals that the detection of PSH is clinical by exclusion and that this detection and therapeutic efficacy depend, in association, on the recognition of typical clinical manifestations and immediate treatment to prevent further damage and prolonged hospitalization $(3,16,17)$.

The PSH-AM is useful as a method for early diagnosis, analysis of the severity and probable approach and treatment efficacy $(3,11)$. Associated with this, the evaluation of adrenergic levels and febrile episodes about three days after ICU admission are predictors of dysautonomia (3).

\section{Possible differential diagnoses}

Neuroleptic Malignant Syndrome, Malignant Hyperthermia, Seizures, Autonomic Dysflexia, Central Fever, Infection, Spinal Cord Injury, and Cushing's Reflex are conditions whose pathophysiological and manifestative pattern may resemble Disautonomia $(3,19)$.

\section{Drug and non-drug treatment of pediatric patient}

The management of pediatric patients includes pharmacological and non-pharmacological interventions aimed at reducing sources of triggering of clinical manifestations and attenuation of sympathetic noradrenergic hyperactivity $(16,19)$. Nondrug therapeutic measures include: thermal control of the environment and use of ventilator or cooling blanket to contain the hyperthermia; environment with low visual and sound stimulation; and body movement exercises and massages $(10,16,17)$.

Regarding the drug approach, it is based on mitigating the symptoms and requires caution regarding the dosages of drugs in order to avoid overeating and unexpected side effects, include the use of: propranolol, clonidine, gabapentin, baclofen, benzodiazepines and opioids as morphine which are the last resort $(3,10,15,16,19)$. Basically, morphine is shown to be one of the main drugs because it not only assists in pain control but also modifies the consequent changes in autonomic activity, by suppressing the sympathetic axis (8). In addition, 


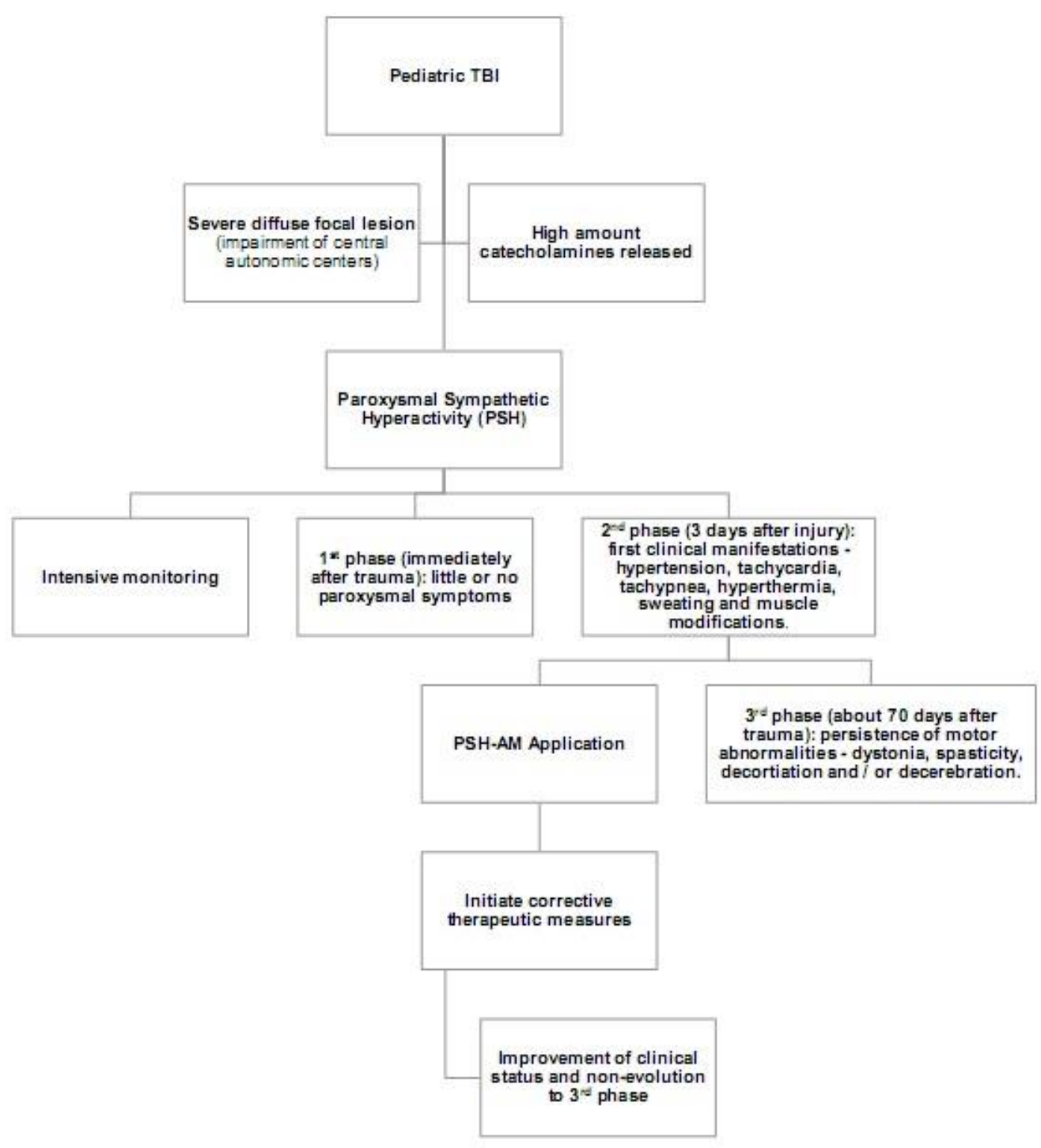

Figure 1: Pathophysiological algorithm of the PSH

medications such as: propranolol can reduce catecholamines and consequently cardiac function and catabolism; intrathecal baclofen (Gaba B agonist - inhibitor of medullary interneurons) and gabapentin (brainstem inhibitor) have positive effects on spasticity, pain and altered heart rate, being the second most effective according to the literature $(8,12,20)$. There are also benzodiazepines, GABAergic agonists, which acts on blood pressure alteration and psychomotor agitation (20).

Given this, the most appropriate in the decisionmaking of the therapy to be used is to select target signs and symptoms, evaluating each case according to its clinical uniqueness, allowing the determination of early PSH $(3,19)$. In order to avoid the adoption of negligent conduct and excessive and excessive medicalization of the child (19).

\section{Conclusion}

Severe TBI, which is a common pediatric emergency, can be considered a predictor of the evolution of $\mathrm{PSH}$, especially when considering DAI. Finally, as much as there is no unanimous consensus on the diagnosis, PSH-AM is a reliable alternative for professionals to adopt appropriate procedures to minimize the damage to the child's organic state after a severe neurological injury and make the dysautonomic aggravation unfeasible (Figure 1).

\section{Disclosures}

The authors declare that they have no conflict of interest related to this article. 


\section{Abbreviation list}

ADNS: Autonomic Division of the Nervous System

CCS: Clinical Characteristics Scale

DAl: diffuse axonal injury

DPT: Diagnostic Probability Tool

ICU: Intensive Care Units

PSH: Paroxysmal Sympathetic Hyperactivity

PSH-AM: PSH-Assessment Measure

TBI: Traumatic brain injury

\section{References}

1. Junior LRM, Paiva WS, Andrade AF, Amorim RLO, Fonoff ET, Teixeira MJ. Uso de morfina peridural em pacientes com disautonomia após traumatismo craniencefálico. Arq Bras Neurocir, 2011; 30(1): 7-10. 2. Araújo AQ-C. Prionic diseases. Arq. NeuroPsiquiatr. São Paulo: 2013 Sept; 71 (9):731-737.

3. Godo S, Irino S, Nakagawa A, Kawazoe Y, Fujita M, Kudo D, et al. Diagnosis and Management of Patients with Paroxysmal Sympathetic Hyperactivity following Acute Brain Injuries Using a Consensus-Based Diagnostic Tool: A Single Institutional Case Series. Tohoku J Exp Med. 2017 ; 243(1):11-18.

4. Carvalho LFA, Affonseca CA, Guerra SD, Ferreira AR, Goulart EMA. Traumatismo Cranioencefálico Grave em Crianças e Adolescentes. Revista Brasileira de Terapia Intensiva, 2007, Jan - Mar; 19 (1): 98-106. 5. Ghizoni E, Fraga AMA, Baracat ECE, Joaquim AF, Fraga GP, Rizoli S, et al. Indicações de tomografia de crânio em crianças com trauma cranioencefálico leve. Rev. Col. Bras. Cir. 2013; 40(6): 515-519.

6. Couto PT, Fiorentin RDA, Dalcin TC. Criança com traumatismo crânio-encefálico na emergência hospitalar: quando tomografar?. Acta méd. Porto Alegre: 2015; 36 (6):1-6.

7. Melo JRT, Santana DLP, Pereira JLB, Ribeiro TF. Traumatismo craniencefálico em crianças e adolescentes na cidade do salvador - Bahia. Arq Neuropsiquiatr, 2006 Mar; 64(4):994-996.

8. Magalhães FN, Paiva WS, Andrade AF, Bor-SengShu E, Faleiro RM, Figueiredo EG et al. Considerações sobre a síndrome da disfunção autonômica pós traumatismo cranioencefálico: fisiopatologia e tratamento. Arq Bras Neurocir, 2012; 31(2): 75-80.
9. Mendes PD, Maciel MS, Brandão MVT, Fernandes PCR, Antonio VE, Kodaira SK et al. Distúrbios da Consciência Humana - Parte 2 de 3: A Abordagem dos Enfermos em Coma. Rev Neurocienc, 2012;20(4):576-583.

10. Totikov A, Boltzmann M, Schmidt SB, Rollnik JD. Influence of paroxysmal sympathetic hyperactivity (PSH) on the functional outcome of neurological early rehabilitation patients: a case control study. BMC Neurology, 2019;19(162):1-10.

11. Samuel S, Lee M, Brown RJ, Choi HÁ, Baguley IJ. Incidence of paroxysmal sympathetic hyperactivity following traumatic brain injury using assessment tools. Taylor \& Francis Group, 2018;32:1115-1121.

12.Meyer KS. Understanding paroxysmal sympathetic hyperactivity after traumatic brain injury. SNI: Neurosciences Nursing, 2014; 5(13):490-492.

13. Godoy DA, Orquera J, Rabinstein AA. Síndrome de hiperatividade simpática paroxística causada por síndrome da embolia gordurosa. Rev Bras Ter Intensiva. 2018; 30(2):237-243.

14. Gentile JKA, Himuro HS, Rojas SSO, Veiga VC, Amaya LEC, Carvalho JC. Condutas no paciente com trauma crânioencefálico. Rev Bras Clin Med. São Paulo, 2011;9(1):74-82.

15. Deepika A, Mathew MJ, Kumar AS, Devi BI, Shukla D. Paroxysmal sympathetic hyperactivity in pediatric traumatic brain injury: A case series of four patients. Autonomic Neuroscience: Basic and Clinical. 2015 May-Aug; p.1-3.

16. Burton JM, Morozova OM. Calming the Storm: Dysautonomia for the Pediatrician. Curr Probl Pediatr Adolesc Health Care. Washington, 2017 July; 47 (7): 145-150.

17. Letzkus L, Keim-Malpass J, Anderson J, Kennedy C. Paroxysmal Sympathetic Hyperactivity in Children: An Exploratory Evaluation of Nursing Interventions. Journal of Pediatric Nursing, 2017; 34: 17-21.

18. Novak P. Autonomic Disorders. The American Journal of Medicine, 2019 April; 132(4):420-436.

19. Blackman JA, Patrick PD, Buck ML, Rust RS. Paroxysmal Autonomic Instability With Dystonia After Brain Injury. Arch Neurol, Mar 2004; 61: 321-328.

20. Choi A, Jeon SB, Samuel S, Allison T, Lee K. Paroxysmal Sympathetic Hyperactivity After Acute Brain Injury. Curr Neurol Neurosci Rep, 2013; 13:370:1-10. 